\title{
Factors associated with adherence to oral antihyperglycemic monotherapy in patients with type 2 diabetes
}

This article was published in the following Dove Press journal:

Patient Preference and Adherence

28 January 2015

Number of times this article has been viewed

\author{
Kaan Tunceli' \\ Changgeng Zhao' \\ Michael J Davies ${ }^{2}$ \\ Kimberly G Brodovicz ${ }^{3}$ \\ Charles M Alexander ${ }^{4}$ \\ Kristy Iglay' \\ Larry Radican' \\ 'Global Health Outcomes, \\ Merck \& Co, Inc, Whitehouse \\ Station, NJ, USA; ${ }^{2}$ Global Scientific \\ and Medical Publications, Merck \& \\ Co, Inc, Whitehouse Station, NJ, USA; \\ ${ }^{3}$ Global Epidemiology, Merck \& Co, \\ Inc, Whitehouse Station, NJ, USA; \\ ${ }^{4}$ Global Medical Affairs, Merck \& Co, \\ Inc, Whitehouse Station, NJ, USA
}

Correspondence: Kaan Tunceli Global Health Outcomes, Merck \& Co., Inc., Mailstop 2A-16, 35I North Sumneytown, North Wales, PA 194542505, USA

Tel +l 2673050789

Email kaan_tunceli@merck.com
Aim: To estimate the rate of adherence to oral antihyperglycemic monotherapy for patients with type 2 diabetes in the US and describe factors associated with adherence in these patients.

Materials and methods: In this retrospective cohort analysis, patients aged 18 years or older with a type 2 diabetes diagnosis received between 1 January 2007 and 31 March 2010 were identified using a large US-based health care claims database. The index date was defined as the date of the first prescription for oral antihyperglycemic monotherapy during this period. Patients had to have continuous enrollment in the claims database for 12 months before and after the index date. Adherence was assessed using proportion of days covered (PDC) and an adjusted logistic regression analysis was performed to evaluate factors associated with adherence ( $\mathrm{PDC} \geq 80 \%$ ).

Results: Of the 133,449 eligible patients, the mean age was 61 years and 51\% were men. Mean PDC was $75 \%$ and the proportion of patients adherent to oral antihyperglycemic monotherapy was 59\%. Both mean PDC and PDC $\geq 80 \%$ increased with increasing age and the number of concomitant medications, and were slightly higher in men compared to women. Results from the logistic regression demonstrate an increased likelihood of non-adherence for patients who were younger, new to therapy, on a twice-daily dose, female, or on fewer than three concomitant medications compared to their reference groups. Higher average daily out-of-pocket pharmacy expense was also associated with an increased likelihood of non-adherence. All results were statistically significant $(P<0.05)$.

Conclusion: Patient characteristics, treatment regimens, and out-of-pocket expenses were associated with adherence to oral antihyperglycemic monotherapy in our study.

Keywords: compliance, proportion of days covered, PDC, MPR, T2DM, treatment, medication

\section{Introduction}

Type 2 diabetes is a complex chronic disease characterized by a failure to maintain physiologic glucose control. In 2012 alone, diabetes affected an estimated 24.1 million adults in the US, representing $11 \%$ of the adult population. This number appears to be on the rise, with 29.6 million cases expected by $2030 .{ }^{1}$ Due to the sheer volume of those affected and the extent of the complications associated with diabetes, the demand for health care resources is substantial. In 2012, the US spent an estimated $\$ 245$ billion on health care expenditures for diagnosed diabetes. ${ }^{2}$

Although type 2 diabetes is progressive in nature, pharmacologic therapy can help control glucose, blood pressure, and cholesterol, thereby improving outcomes such as diabetic complications and mortality. ${ }^{3-6}$ However, in order to maximize long-term clinical benefits, adherence to these medications is critical. Randomized clinical trials have demonstrated the efficacy of many widely available therapeutic options for type 2 
diabetes, but these trials are conducted in highly-controlled settings. In addition, non-adherent study participants are generally not allowed to continue study participation, resulting in very high medication adherence rates. Previous retrospective observational studies have shown that adherence rates vary widely in patients with diabetes, but remain suboptimal, ranging from $31 \%$ to $87 \% .^{7}$ Furthermore, a recent literature review by Cramer et $\mathrm{al}^{8}$ demonstrated that better medication adherence positively impacted patient outcomes in the majority of studies examined, but across studies of patients with diabetes, only $58 \%$ of patients were considered adherent to their oral antihyperglycemic therapy.

Many factors have been cited as influencing medication adherence, especially commitment to take the medication to treat the disease, concern about side effects, and cost of the medication. ${ }^{9}$ In patients with diabetes, the scope of the problem is broad and multifaceted, presenting an extraordinary challenge for physicians and patients alike. Not only are factors such as a patient's knowledge of diabetes and perceptions of the benefit of medication playing a role, but these factors interplay with medication costs, real or possible future side effects, frequency of dosing, complexity of dosing, patient characteristics, and a multitude of other factors to determine medication adherence behavior. ${ }^{7,9-11}$ The objective of this study was to examine medication adherence to oral antihyperglycemic monotherapy in a commercial US cohort of patients with type 2 diabetes and to identify factors associated with non-adherence.

\section{Materials and methods}

In this retrospective cohort study, data were extracted from the Truven Health MarketScan ${ }^{\circledR}$ Commercial Claims and Encounters and Medicare Supplemental and Coordination of Benefits Databases between 1 January 2006 and 3 March 2011. The MarketScan databases include patient-level paid, medical, and pharmacy claims from 12 national and regional health plans, representing 110 million covered participants across the US.

\section{Patient selection}

Patients with a pharmacy claim for metformin, sulfonylurea, thiazolidinedione or dipeptidyl peptidase-4 inhibitor as monotherapy between 1 January 2007 and 31 March 2010 (index period) were selected from the database. Treatments were considered monotherapy when only a single oral antihyperglycemic agent (OAHA) was available for any given day. The index date was defined as the date of the first prescription for oral antihyperglycemic monotherapy during the index period. Those aged 18 years or older with a type 2 diabetes diagnosis during the 12 month pre-index period were then identified using the International Classification of Disease, ninth Revision, Clinical Modification (ICD-9-CM) diagnostic codes (250.x0 and 250.x2). Patients were required to have continuous enrollment in the database during the 12 months preceding (baseline period) and 12 months following the index date (follow-up period). Patients were excluded from the study if they had at least one claim for type 1 diabetes (ICD-9-CM codes 250.x1 and 250.x3), their dosing regimen (once or twice daily) could not be determined at the index date, they switched between once- and twice-daily dosing regimens during the follow-up period, or they violated the monotherapy requirement during the follow-up period. Patients who switched monotherapy agents during follow-up were included in the study as long as they continued to be on monotherapy; however, their therapy was categorized as "Other" instead of as their index monotherapy class. If patients switched from oral antihyperglycemic monotherapy to insulin or added insulin to their therapy during follow-up, they were excluded. If dosing regimen (once daily versus [vs] twice daily) was not specified in the database for a particular patient, it was defined based on prescribing information. Previous treatment status (new to oral antihyperglycemic monotherapy vs previously on oral antihyperglycemic monotherapy treatment) was defined based on whether a patient had a pharmacy claim for OAHA monotherapy in the 12 month baseline period.

\section{Adherence assessment}

Patients were followed for 12 months after the initiation of oral antihyperglycemic monotherapy to determine their medication adherence (Figure 1). Proportion of days covered (PDC) was used to quantify medication adherence and was calculated as the number of days with the drug on-hand divided by 365 days of follow-up. In our analysis, PDC was calculated as both a continuous and dichotomous measure. Patients were considered adherent if their PDC was $\geq 80 \%$, which is a commonly used threshold to define adherence. ${ }^{8}$

\section{Statistical analysis}

Descriptive analyses were conducted to examine the baseline characteristics of patients on oral antihyperglycemic monotherapy. Adherence was calculated overall and in subgroups stratified by sex, age $(<45,45-64$, and $\geq 65$ years), and the number of concomitant therapies $(0,1,2$, and $\geq 3)$. Concomitant therapies were defined as diuretics, antiplatelet agents, cardiac medications, dyslipidemic drugs, and 


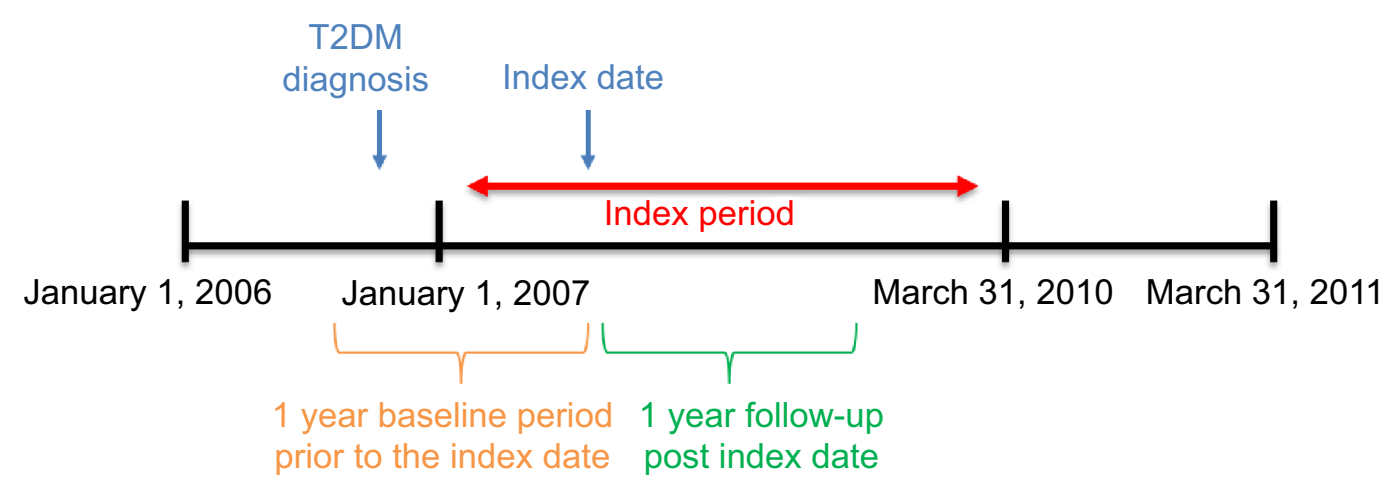

Figure I Study observation period for inception cohort.

Notes: Index date is the first prescription date in the index period. If patients are eligible multiple times for study inclusion during the observation period, only the first qualified medication episode is included.

Abbreviation: T2DM, type 2 diabetes mellitus.

antihypertensive medications. All patient and medicationrelevant characteristics were assessed during the 12 month baseline period. A multivariate logistic regression analysis was conducted to assess baseline patient and medicationrelated factors (ie, age, sex, previous treatment status [new to or previously on monotherapy], monotherapy dosing regimen [once daily or twice daily], average daily out-of pocket pharmacy expenses for oral antihyperglycemic monotherapy, and the number of concomitant prescriptions $[0,1,2$, or $\geq 3]$ ) associated with adherence (PDC $\geq 80 \%$ ), after adjusting for baseline comorbid conditions (myocardial infarction, cerebrovascular disease, congestive heart failure, chronic pulmonary disease, dementia, mild liver disease, moderate/severe liver disease, peptic ulcer disease, peripheral vascular disease, rheumatologic disease, renal disease, leukemia, lymphoma, metastatic solid tumor, any tumor, and hemiplegia/paraplegia).

\section{Results}

Of the 133,449 eligible patients, $51 \%$ were male, $39 \%$ were on once-daily oral antihyperglycemic monotherapy, and $49 \%$ were taking $\geq 3$ concomitant medications. The mean age (standard deviation) of the cohort was 60.7 (12.6) years, with $35 \%$ of patients over the age of 65 (Table 1). Overall, mean PDC was $75 \%$ and the proportion of patients adherent to oral antihyperglycemic monotherapy ( $\mathrm{PDC} \geq 80 \%$ ) was $59 \%$. While only $37 \%$ of patients $<45$ years of age were considered adherent to oral antihyperglycemic monotherapy, this value rose to $70 \%$ for those 65 years or older. Both mean $\mathrm{PDC}$ and $\mathrm{PDC} \geq 80 \%$ increased with increasing age and the number of concomitant medications (Figure 2). Mean PDC and $\mathrm{PDC} \geq 80 \%$ were also slightly higher in men compared to women $(\mathrm{PDC}=76 \%$ vs $74 \%$ and $\mathrm{PDC} \geq 80 \%=60 \%$ vs
$57 \%$, respectively; $P<0.0001$ for both). When stratified by age and sex combined, mean PDC and PDC $\geq 80 \%$ were still shown to increase with increasing age for each sex group (Figure 3).

Results from the multivariate logistic regression demonstrated that numerous factors are associated with non-adherence (Figure 4). Younger age, new to monotherapy status, twice-daily dose of OAHA, female sex, fewer concomitant medications, and higher average daily out-of-pocket pharmacy expenses for oral antihyperglycemic monotherapy were all independently associated with non-adherence.

\section{Discussion}

Although previous studies of adherence to antihyperglycemic medications have demonstrated that better adherence is associated with improved glycemic control and decreased health care resource utilization, medication adherence rates remain low in this population. ${ }^{12,13}$ In the present study, adherence to oral antihyperglycemic monotherapy was evaluated in patients with type 2 diabetes using a large, recent US-based commercial database.

Our study showed that mean adherence to oral antihyperglycemic monotherapy as measured by PDC was $75 \%$ and the proportion of patients considered adherent to oral antihyperglycemic monotherapy ( $\mathrm{PDC} \geq 80 \%$ ) was only $59 \%$, demonstrating suboptimal adherence in this population. These results are consistent with a recent study by Curkendall et $\mathrm{al}^{14}$ that evaluated predictors of medication adherence in patients with type 2 diabetes using the same insurance claims database. Although adherence in Curkendall et al's study was slightly lower than our study, that study included those on monotherapy or combination therapy, whereas we only included those on monotherapy. 
Table I Patient characteristics at baseline

\begin{tabular}{|c|c|c|}
\hline & \multicolumn{2}{|c|}{ Overall $(N=133,499)$} \\
\hline & $\mathbf{n}$ & Mean (SD) or \% \\
\hline Mean age (years) & 133,499 & $60.7(12.6)$ \\
\hline \multicolumn{3}{|l|}{ Age groups (year) } \\
\hline$<45$ & $\mathrm{II}, 844$ & $8.9 \%$ \\
\hline $45-64$ & 75,254 & $56.4 \%$ \\
\hline$\geq 65$ & 46,401 & $34.8 \%$ \\
\hline \multicolumn{3}{|l|}{ Sex } \\
\hline Female & 65,955 & $49.4 \%$ \\
\hline Male & 67,544 & $50.6 \%$ \\
\hline \multicolumn{3}{|l|}{ Concomitant medications } \\
\hline None & 12,946 & $9.7 \%$ \\
\hline I & 23,899 & $17.9 \%$ \\
\hline 2 & 31,597 & $23.7 \%$ \\
\hline$\geq 3$ & 65,057 & $48.7 \%$ \\
\hline \multicolumn{3}{|c|}{ Oral antihyperglycemic Agents (OAHA) } \\
\hline Metformin & 94,529 & $70.8 \%$ \\
\hline TZD & 16,290 & $12.2 \%$ \\
\hline SU & 15,589 & $11.7 \%$ \\
\hline DPP-4i & 4,382 & $3.3 \%$ \\
\hline Others* & 2,709 & $2.0 \%$ \\
\hline \multicolumn{3}{|l|}{ Dosing frequency of OAHA } \\
\hline Once daily & 52,633 & $39.4 \%$ \\
\hline Twice daily & 80,866 & $60.6 \%$ \\
\hline \multicolumn{3}{|l|}{ Comorbidities } \\
\hline Myocardial infarction & 3,078 & $2.3 \%$ \\
\hline Cerebrovascular & 6,080 & $4.6 \%$ \\
\hline Congestive heart failure & 7,675 & $5.7 \%$ \\
\hline Chronic pulmonary disease & 7,925 & $5.9 \%$ \\
\hline Dementia & 761 & $0.6 \%$ \\
\hline Leukemia & 268 & $0.2 \%$ \\
\hline Lymphoma & 613 & $0.5 \%$ \\
\hline Metastatic solid tumor & 514 & $0.4 \%$ \\
\hline Mild liver & 3,320 & $2.5 \%$ \\
\hline Peptic ulcer disease & 682 & $0.5 \%$ \\
\hline Peripheral vascular disease & 6,570 & $4.9 \%$ \\
\hline Rheumatologic disease & 2,189 & $1.6 \%$ \\
\hline Renal disease & 4,206 & $3.2 \%$ \\
\hline Moderate/severe liver disease & $64 I$ & $0.5 \%$ \\
\hline Any tumor & 10,894 & $8.2 \%$ \\
\hline Hemiplegia/paraplegia & 3,111 & $2.3 \%$ \\
\hline \multirow{3}{*}{\multicolumn{3}{|c|}{$\begin{array}{l}\text { Average daily out-of-pocket pharmacy } \\
\text { expenses for oral antihyperglycemic } \\
\text { monotherapy }\end{array}$}} \\
\hline & & \\
\hline & & \\
\hline Mean (SD) & 133,499 & $\$ 0.25(0.33)$ \\
\hline Median (Interquartile range) & 133,499 & $\$ 0.17(0.11-0.28)$ \\
\hline
\end{tabular}

Note: *Individuals who switch therapies during follow-up without violating the monotherapy requirement.

Abbreviations: SD, standard deviation; TZD, thiazolidinedione; SU, sulfonylurea; DPP-4i, dipeptidyl peptidase-4 inhibitor.

Since patients on monotherapy generally have higher adherence rates, ${ }^{14,15}$ this may explain the difference in results between these two studies. In addition to the study by Curkendall et al, Cramer et $\mathrm{al}^{8}$ assessed the rate of adherence to OAHAs, as measured by medication possession ratio, in published studies between January 2000 and November 2005.
Since patients often refill their prescription before completing their current fill, they are automatically credited with additional days of supply, thereby potentially inflating the medication possession ratio estimate. In contrast, PDC looks at each day during follow-up and determines if a prescription was on hand for that particular day.

Another objective of our analysis was to examine factors associated with non-adherence to oral antihyperglycemic monotherapy in patients with type 2 diabetes. In the present study, age, dosing regimen, sex, number of concomitant medications, previous treatment status, and out-of-pocket pharmacy expenses all played a role in adherence behavior.

In accordance with previous studies, ${ }^{14,16,17}$ there was a distinct trend for increased adherence with increasing age, with the oldest age ( $\geq 65$ years) group in the present study having better adherence than the younger age groups $(<45$ years and 45-64 years). Currently, the literature is mixed regarding the association between sex and adherence. Although we found that women were significantly less likely to be adherent than men based on the logistic regression model, the absolute values for mean PDC and PDC $\geq 80 \%$ were similar for men and women. In the Curkendall et al study,$^{14}$ the likelihood of adherence was significantly higher among men than women with type 2 diabetes. In contrast, Donnan et al, ${ }^{18} \mathrm{Hertz}$ et al, ${ }^{16}$ and Tiv et a ${ }^{17}$ all reported no significant difference in adherence rates for men and women.

In the present study, patients on once daily dosing were shown to have better adherence than those on twice daily dosing. A recent meta-analysis evaluated the effect of dosing frequency (once daily, twice daily, thrice daily, and four times daily) on medication adherence in patients with acute and chronic diseases. Five studies were found presenting data on adherence to type 2 diabetes medications. The pooled results of two studies showed that once daily dosing was associated with a higher rate of adherence compared to more than once daily dosing. Due to differing assessment methods, the remaining studies could not be included in the pooled estimate; however, in each study, once daily dosing had better adherence rates than twice or three-times daily dosing. ${ }^{19}$ Furthermore, not only does dosing frequency play a role in adherence, but the number of concomitant medications does as well. The present study showed a significant inverse relationship between adherence and number of concomitant medications, which is consistent with previous literature. ${ }^{18}$

Limited data are available examining the relationship between adherence and previous treatment status in patients with diabetes. In the present study, patients new to oral antihyperglycemic monotherapy demonstrated lower medication 


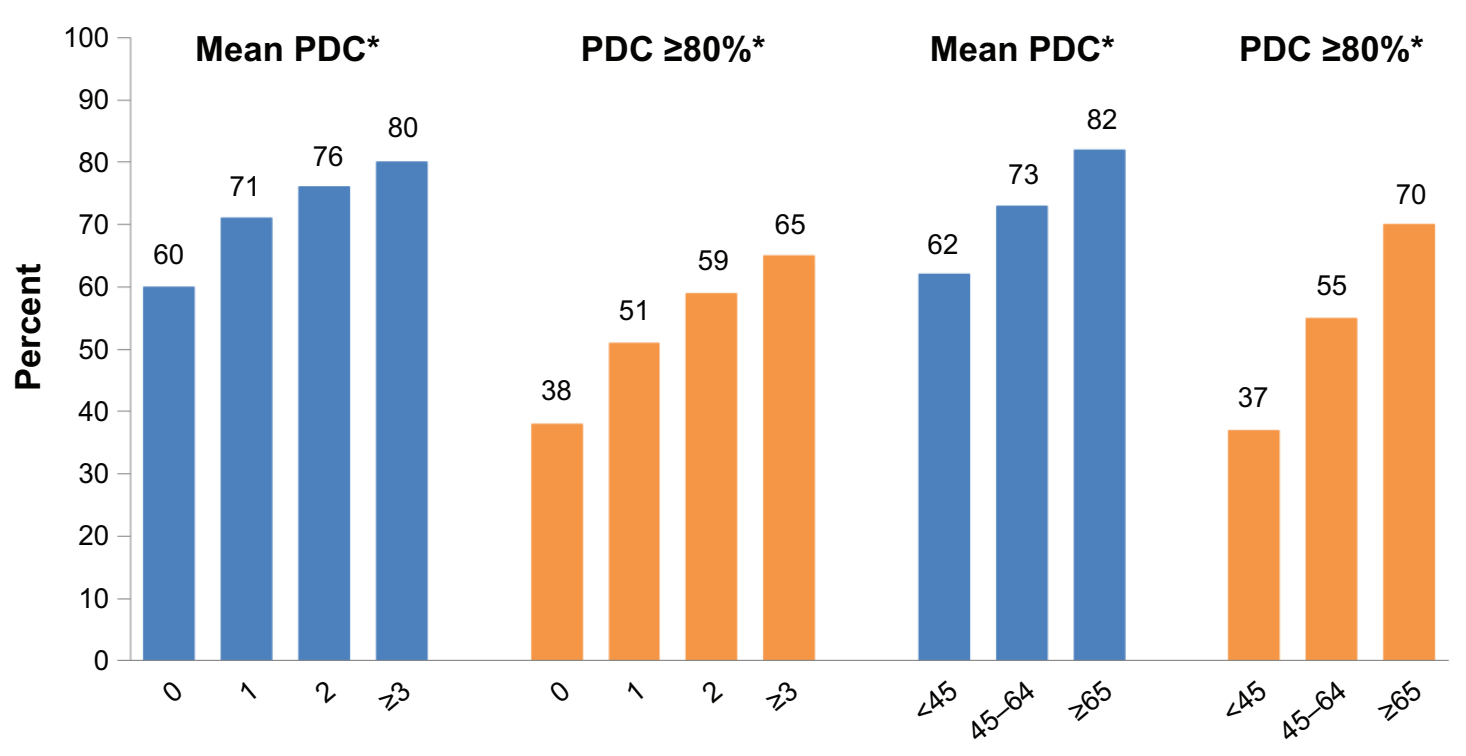

Concomitant medications ${ }^{\dagger}$

Age groups ${ }^{\ddagger}$

Figure 2 Adherence by concomitant medications and age groups.

Notes: $* P<0.0001$ versus reference group; ${ }^{\dagger}$ reference group for concomitant medications is $\geq 3$ medications; ${ }^{\ddagger}$ reference group for age is $\geq 65$ years.

Abbreviation: PDC, proportion of days covered.

adherence rates when compared to those who were previously on therapy. Although this link has not been widely studied, there are many potential reasons for this association. A main factor that is often cited as a barrier to adherence is a patient's lack of confidence in the benefit of their medication. . $^{71,20}$ Moreover, those who were previously on treatment are likely to be older, which increases their adherence compared to those who are new to therapy. It is important to note that the number of concomitant medications, previous treatment, and age are all somewhat correlated, but the exact interaction between these factors could not be examined in this observational study.

In addition to previous treatment status, a patient's outof-pocket pharmacy expense for OAHAs was shown to be

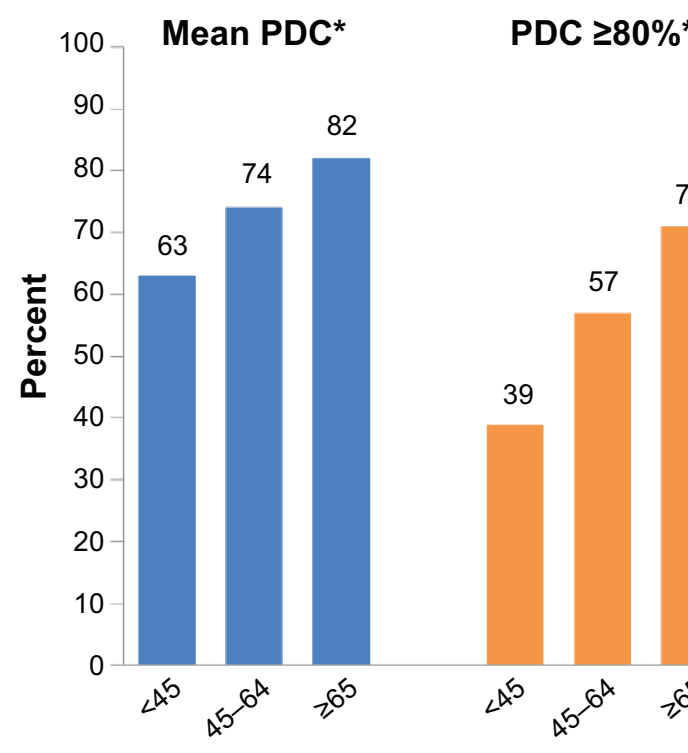

Age groups, male
Mean PDC*

81 71

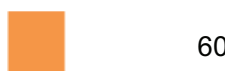

60
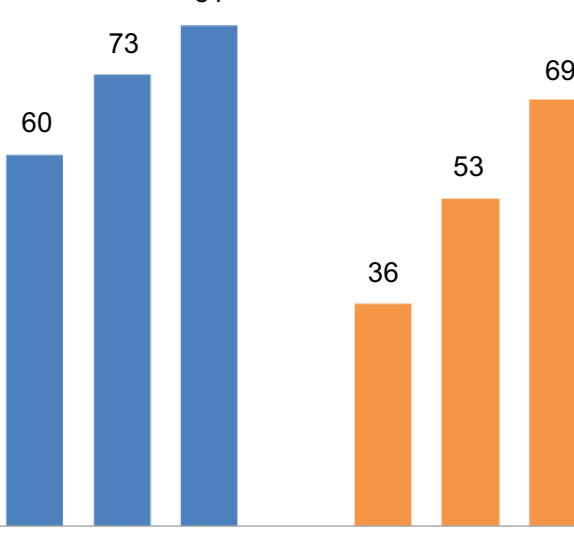

$\angle x^{5} \quad 4^{5^{6 x}} 77^{65}$

Age groups, female
PDC $\geq 80 \%$ *

69

Figure 3 Adherence by age group and sex.

Note: $* P<0.000$ I versus reference group ( $\geq 65$ years).

Abbreviation: PDC, proportion of days covered. 


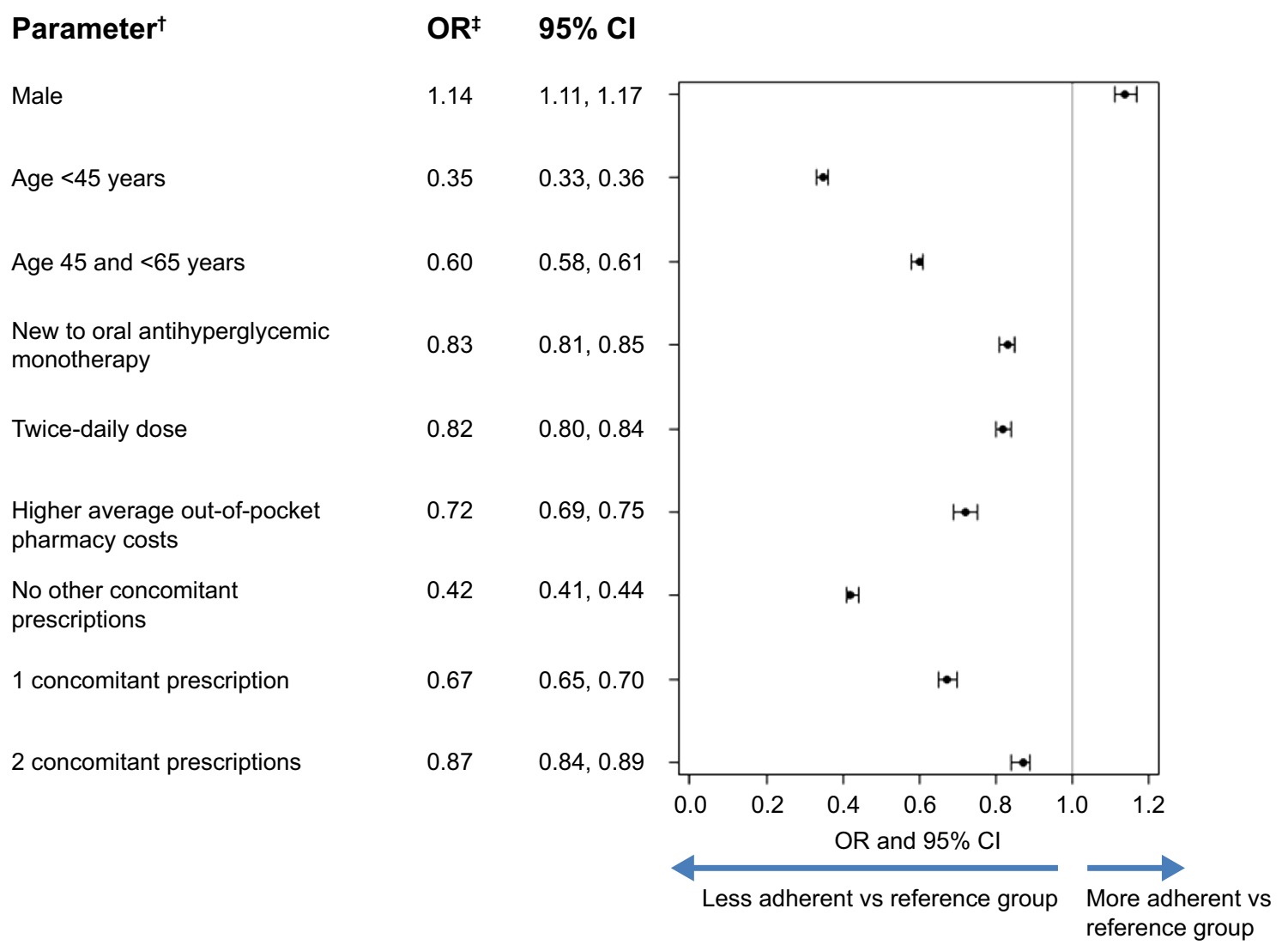

Figure 4 Logistic regression results for factors associated with adherence to oral antihyperglycemic monotherapy (PDC $\geq 80 \%$ )*

Notes: *Adjusted for baseline characteristics and comorbid conditions; ${ }^{\dagger}$ reference categories: female, age $\geq 65$ years, previously on oral antihyperglycemic monotherapy treatment, once-daily dose, and $\geq 3$ concomitant prescriptions; ${ }^{\ddagger}$ an $O R>I$ indicates a positive association with adherence and an $O R<I$ indicates a negative association with adherence.

Abbreviations: PDC, proportion of days covered; OR, odds ratio; $\mathrm{Cl}$, confidence interval; vs, versus.

a significant barrier to adherence with diabetes medications in the present study. This has been cited in previous studies and is particularly important in those with low socioeconomic status or inadequate health care coverage. . $11,14,17,21,22$ Patients with type 2 diabetes who had financial difficulties, for example, had 1.7 times the likelihood of non-adherence compared to those without financial difficulties. ${ }^{17}$ Additionally, Curkendall et al ${ }^{14}$ demonstrated a statistically significant relationship between cost-sharing and adherence in patients with type 2 diabetes, with each $\$ 1$ increase in patient cost sharing decreasing the odds of being adherent by $1 \%$. Furthermore, a systematic literature review by Eaddy et al ${ }^{22}$ found 160 publications that assessed the relationship between changes in cost sharing and adherence. Of those, $85 \%$ showed that increasing a patient's share of medication costs was associated with a significant decrease in adherence.

It is important to note that several limitations are present in this study. First, measures of adherence were based on pharmacy claims data, which only show that a prescription was filled. It is unknown whether the prescription was taken by the patient or taken as prescribed. Second, the MarketScan databases are representative of the national commercially insured population and those who have both Medicare and supplemental coverage. Because of this, our findings might not be generalizable to those covered by Medicare only, Medicaid, or those who are uninsured. Patients who did not fill their prescription at a pharmacy or who did not have an insurance claim filed were not included. Third, unobserved factors might have confounded the study results if they were correlated with both our predictors of interest and adherence, and were not truly random. Nevertheless, based on the study design, we could not assess the extent of such factors within the database. Fourth, combination therapy is common in type 2 diabetes, but this study only focuses on those patients taking oral monotherapy. Therefore, the results might not be generalizable to all patients with type 2 diabetes. Fifth, if a pharmacy claim is not filed for medication or if a prescription was filled outside of the 12 month baseline period, a patient would not be captured as previously treated. Lastly, because we required patients to have continuous enrollment in the 
MarketScan databases for 12 months following the index date, these patients might be more adherent than the general population of patients with type 2 diabetes mellitus. This would cause us to overestimate adherence in this study.

In conclusion, adherence to oral antihyperglycemic monotherapy was suboptimal in our study for patients with type 2 diabetes. Medication adherence in this population appeared to be multifactorial and was associated with patient characteristics, treatment regimens, and the patient's out-ofpocket pharmacy expenses.

\section{Acknowledgment}

This study was funded by Merck \& Co., Inc.

\section{Disclosure}

$\mathrm{KT}, \mathrm{CZ}, \mathrm{MJD}, \mathrm{KGB}, \mathrm{CMA}$, KI and LR all declare that they are/were full-time employees of Merck \& Co., Inc., Whitehouse Station, NJ at the time of the analysis and may potentially own stock and/or hold stock options in the company.

\section{References}

1. International Diabetes Federation [homepage on the Internet]. IDF Diabetes Atlas, 5th edition. Diabetes Federation, 2011. Available from: http://www.idf.org/diabetesatlas

2. American Diabetes Association. Economic costs of diabetes in the U.S. in 2012. Diabetes Care. 2013;36(4):1033-1046.

3. Holman RR, Paul SK, Bethel MA, Matthews DR, Neil HA. 10-year follow-up of intensive glucose control in type 2 diabetes. N Engl J Med. 2008;359(15):1577-1589.

4. No authors listed. Intensive blood-glucose control with sulphonylureas or insulin compared with conventional treatment and risk of complications in patients with type 2 diabetes (UKPDS 33). The UK Prospective Diabetes Study (UKPDS) Group. Lancet. 1998;352(9131): 837-853.

5. The ADVANCE Collaborative Group; Patel A, MacMahon S, et al. Intensive blood glucose control and vascular outcomes in patients with type 2 diabetes. $N$ Engl J Med. 2008;358(24):2560-2572.

6. Gaede P, Lund-Andersen H, Parving HH, Pedersen O. Effect of a multifactorial intervention on mortality in type 2 diabetes. $N$ Engl J Med. 2008;358(6):580-591.

7. Odegard PS, Capoccia K. Medication taking and diabetes: a systematic review of the literature. Diabetes Educ. 2007;33(6):1014-1029.
8. Cramer JA, Benedict A, Muszbek N, Keskinaslan A, Khan ZM. The significance of compliance and persistence in the treatment of diabetes, hypertension and dyslipidaemia: a review. Int J Clin Pract. 2008;62(1):76-87.

9. McHorney CA. The Adherence Estimator: a brief, proximal screener for patient propensity to adhere to prescription medications for chronic disease. Curr Med Res Opin. 2009;25(1):215-238.

10. Nam S, Chesla C, Stotts NA, Kroon L, Janson SL. Barriers to diabetes management: patient and provider factors. Diabetes Res Clin Pract. 2011; 93(1):1-9.

11. Nau DP. Recommendations for improving adherence to type 2 diabetes mellitus therapy - focus on optimizing oral and non-insulin therapies. Am J Manag Care. 2012;18(3 Suppl):S49-S54.

12. Aikens JE, Piette JD. Longitudinal association between medication adherence and glycaemic control in Type 2 diabetes. Diabet Med. 2013;30(3):338-344.

13. Asche C, LaFleur J, Conner C. A review of diabetes treatment adherence and the association with clinical and economic outcomes. Clin Ther 2011;33(1):74-109.

14. Curkendall SM, Thomas N, Bell KF, Juneau P, Weiss AJ. Predictors of Medication Adherence in Patients with Type 2 Diabetes Mellitus. Curr Med Res Opin. 2013;29(10):1275-1286.

15. Dailey G, Kim MS, Lian JF. Patient compliance and persistence with antihyperglycemic drug regimens: evaluation of a medicaid patient population with type 2 diabetes mellitus. Clin Ther. 2001;23(8):1311-1320.

16. Hertz RP, Unger AN, Lustik MB. Adherence with pharmacotherapy for type 2 diabetes: a retrospective cohort study of adults with employersponsored health insurance. Clin Ther. 2005;27(7):1064-1073.

17. Tiv M, Viel JF, Mauny F, et al. Medication adherence in type 2 diabetes: the ENTRED study 2007, a French Population-Based Study. PLoS One. 2012;7(3):e32412.

18. Donnan PT, MacDonald TM, Morris AD. Adherence to prescribed oral hypoglycaemic medication in a population of patients with Type 2 diabetes: a retrospective cohort study. Diabet Med. 2002;19(4):279-284

19. Srivastava K, Arora A, Kataria A, Cappelleri JC, Sadosky A, Peterson AM. Impact of reducing dosing frequency on adherence to oral therapies: a literature review and meta-analysis. Patient Prefer Adherence. 2013;7:419-434.

20. Grant RW, Devita NG, Singer DE, Meigs JB. Polypharmacy and medication adherence in patients with type 2 diabetes. Diabetes Care. 2003; 26(5):1408-1412.

21. Gibson TB, Song X, Alemayehu B, et al. Cost sharing, adherence, and health outcomes in patients with diabetes. Am J Manag Care. 2010;16(8):589-600.

22. Eaddy MT, Cook CL, O’Day K, Burch SP, Cantrell CR. How patient cost-sharing trends affect adherence and outcomes: a literature review. P T. 2012;37(1):45-55.
Patient Preference and Adherence

\section{Publish your work in this journal}

Patient Preference and Adherence is an international, peer-reviewed, open access journal that focuses on the growing importance of patient preference and adherence throughout the therapeutic continuum. Patient satisfaction, acceptability, quality of life, compliance, persistence and their role in developing new therapeutic modalities and compounds to optimize

\section{Dovepress}

clinical outcomes for existing disease states are major areas of interest for the journal. This journal has been accepted for indexing on PubMed Central. The manuscript management system is completely online and includes a very quick and fair peer-review system, which is all easy to use. Visit http://www. dovepress.com/testimonials.php to read real quotes from published authors. 